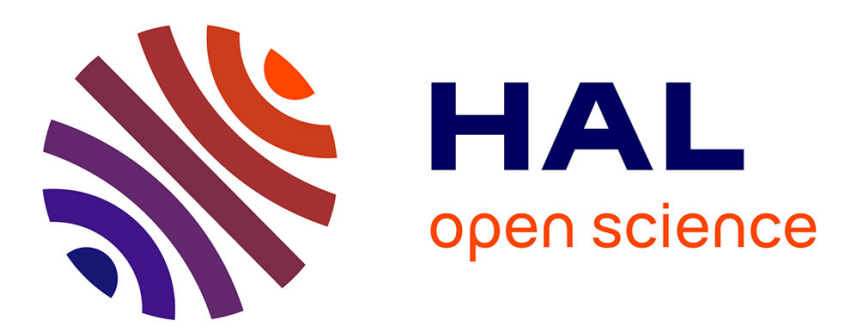

\title{
High temperature thermal diffusivity measurement by the periodic cylindrical method: The problem of contact thermocouple thermometry
}

Benigni P., J. Rogez

\section{- To cite this version:}

Benigni P., J. Rogez. High temperature thermal diffusivity measurement by the periodic cylindrical method: The problem of contact thermocouple thermometry. Review of Scientific Instruments, 1997, 68 (7), pp.2767 - 2773. 10.1063/1.1148193 . hal-01788840

\author{
HAL Id: hal-01788840 \\ https://hal.science/hal-01788840
}

Submitted on 9 May 2018

HAL is a multi-disciplinary open access archive for the deposit and dissemination of scientific research documents, whether they are published or not. The documents may come from teaching and research institutions in France or abroad, or from public or private research centers.
L'archive ouverte pluridisciplinaire HAL, est destinée au dépôt et à la diffusion de documents scientifiques de niveau recherche, publiés ou non, émanant des établissements d'enseignement et de recherche français ou étrangers, des laboratoires publics ou privés. 


\section{AIP | Raterter of}

High temperature thermal diffusivity measurement by the periodic cylindrical method: The problem of contact thermocouple thermometry

P. Benigni and J. Rogez

Citation: Review of Scientific Instruments 68, 2767 (1997); doi: 10.1063/1.1148193

View online: http://dx.doi.org/10.1063/1.1148193

View Table of Contents: http://scitation.aip.org/content/aip/journal/rsi/68/7?ver=pdfcov

Published by the AIP Publishing

\section{Articles you may be interested in}

Thermal modelling comparing high temperature fixed point measurements by contact and non-contact thermometry

AIP Conf. Proc. 1552, 358 (2013); 10.1063/1.4821387

Electrical-optical hybrid pulse-heating method for rapid measurement of high-temperature thermal diffusivity Appl. Phys. Lett. 88, 241901 (2006); 10.1063/1.2211985

Melt temperature field measurement in single screw extrusion using thermocouple meshes

Rev. Sci. Instrum. 75, 4742 (2004); 10.1063/1.1808895

Periodic method: Correction for thermocouple and simultaneous estimation of thermal conductivity and thermal diffusivity

Rev. Sci. Instrum. 75, 2356 (2004); 10.1063/1.1765759

Thermal return reflection method for resolving emissivity and temperature in radiometric measurements J. Appl. Phys. 92, 6302 (2002); 10.1063/1.1516864

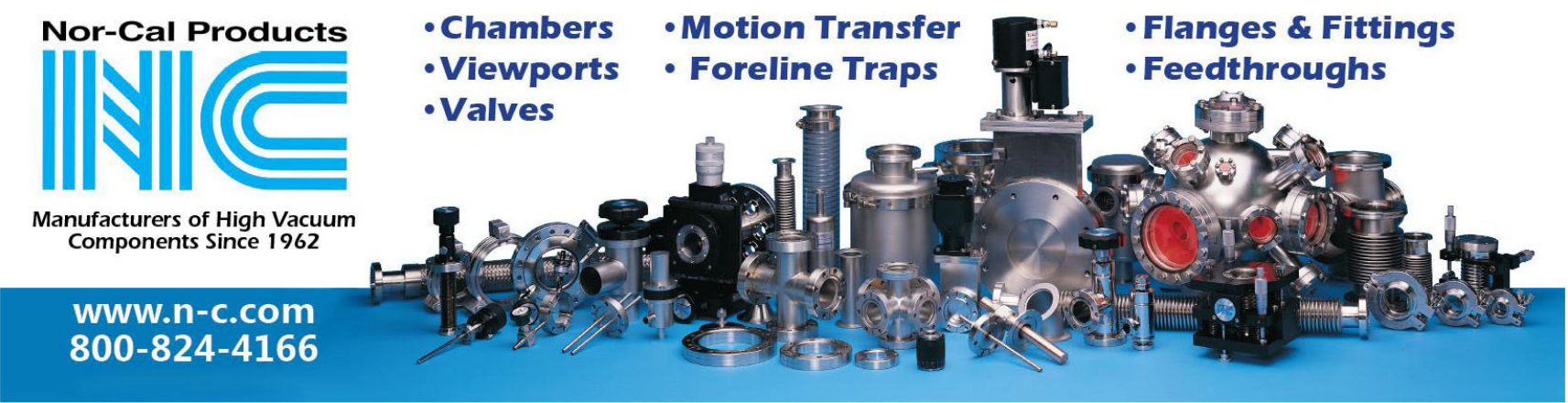




\title{
High temperature thermal diffusivity measurement by the periodic cylindrical method: The problem of contact thermocouple thermometry
}

\author{
P. Benigni and J. Rogez ${ }^{\text {a) }}$ \\ Centre de Thermodynamique et Microcalorimétrie du C.N.R.S., 26 Rue du 141 ème R.I.A., \\ 13003 Marseille, France
}

(Received 25 November 1996; accepted for publication 3 March 1997)

\begin{abstract}
The conditions required for the accurate measurement of the thermal diffusivity of solids at high temperature $(800-1800 \mathrm{~K})$ by the Angström method with cylindrical geometry are studied. It is shown that the main error in the measurement arises from the difficulty in measuring the temperature accurately with contact thermocouples. On the basis of new experimental results on Cecorite and polycrystalline alumina, the effect of the finite size of the sensors and the consequence of the imperfect thermal contact between the sample and the sensors are investigated. Two models which allow a greater insight into the simultaneous influences of both effects are developed. (C) 1997 American Institute of Physics. [S0034-6748(97)03006-2]
\end{abstract}

\section{INTRODUCTION}

An apparatus for thermal diffusivity measurements of refractory solids at high temperature $(800-1800 \mathrm{~K})$ has been recently built. The method and the description of the experimental setup are published elsewhere ${ }^{1}$ with the first measurements on a cordierite based ceramic, the Cecorite $130 \mathrm{P}$.

The principle of the apparatus is the classical Angstrom method adapted to cylindrical geometry. In this method, a thermal wave of angular velocity $\omega$, is generated over the lateral side of the cylindrical sample, the amplitude and the phase of which vary continuously all along the radius. The two measurement points are located at the center of the cylinder and at a distance $d$ from it. The solution of the heat transfer equation relates the thermal diffusivity $K$, through the dimensionless group $(u=\sqrt{\omega / K} d)$, to the phase change $\Phi$ and the amplitude ratio $\Theta$ :

$$
\begin{aligned}
& \Phi(u)=\tan ^{-1}\left(\frac{\operatorname{bei}(u)}{\operatorname{ber}(u)}\right), \\
& \Theta(u)=\frac{1}{\sqrt{\operatorname{ber}^{2}(u)+\operatorname{bei}^{2}(u)}},
\end{aligned}
$$

where ber and bei are the Kelvin functions.

Our primary results on the Cecorite $130 \mathrm{P}$ (Ref. 1) approached but were not in sufficiently close agreement with those of the CODATA program $;^{2}$ moreover, some difficulties remained:

(1) the measurements have been found to be dependent on the frequency of the thermal signal; and

(2) a significant difference between the $K_{\Theta}$ and $K_{\Phi}$ values has been observed.

It is well known that the accuracy of temperature measurements using contact thermocouples is limited by the finite size of the sensors and the imperfect thermal contact between the sensors and the sample. In the field of the periodic method, these effects can be the most significant ones on the measurement uncertainties. ${ }^{3}$ Within the frame of our

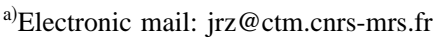

method, the aim of this article is to quantify these sources of error and to check if they can account for the abovementioned phenomena. The study is based on new experimental results and refinement in the mathematical model of the measurement process.

\section{EFFECT OF THE FINITE SIZE OF THE SENSORS}

The distance between the axes of the thermocouples' holes can be accurately estimated within $\pm 0.1 \mathrm{~mm}$, inducing a systematic but moderate error on the diffusivity measurement (e.g., $\approx 1.3 \%$ if $d=15 \mathrm{~mm}$ ). This kind of error analysis is the most commonly used in the description of experimental devices from the literature. ${ }^{4}$ In the model of data processing, $d$ represents the distance between the points where the temperature is effectively measured.

The thermocouples are constructed by inserting $\mathrm{Pt}$ and Pt-Rh $10 \%$ wires $(\varnothing=0.3 \mathrm{~mm})$ in alumina twin-bore tubes (outer $\varnothing=1.7 \mathrm{~mm}$ ). The wires are welded with an oxyacetylene torch, to form a small bead. The use of exposed hot junctions allows the sensors to have very low thermal capacity. The thermocouples are inserted in holes of radius $\left(r_{h}\right.$ $=1 \mathrm{~mm}$ ) drilled in the sample. As a consequence, the location of the contact point between the bead of a thermocouple and the sample is not exactly known. Let $r$ be the radial position of a thermocouple hole, this thermocouple will measure any value of temperature between $\left(r-r_{h}\right)$ and $(r$ $\left.+r_{h}\right){ }^{5}$ Moreover, the size and shape of the bead can vary from one thermocouple to another and the conditions of contact are not controlled. This last point will be the purpose of the next paragraph.

Hence, a knowledge of the distance $d$ is limited by the finite size of the sensors. This geometric effect can be represented in a simple model by a displacement parameter $\epsilon$ of the thermocouples around their expected locations. The magnitude of $\epsilon$ is obviously restricted to the radius of the holes in which the thermocouples are inserted. At the center of the sample, due to cylindrical symmetry, the inner thermocouple lies between 0 and $r_{h}$, yielding a decrease of $d$. The location of the outer thermocouple varies within the range ( $d$ $\left.-r_{h}\right)-\left(d+r_{h}\right)$. For the usual experimental setups the radius 
TABLE I. Diffusivity of Cecorite $130 \mathrm{P}$ obtained with $d=9.3 \mathrm{~mm}$. Each value is an average over at least four measurements.

\begin{tabular}{rccccccccccc}
\hline \hline & \multicolumn{10}{c}{ Period/s } \\
\cline { 2 - 12 }$T / \mathrm{K}$ & \multicolumn{1}{c}{145} & \multicolumn{1}{c}{252} & \multicolumn{2}{c}{333} & \multicolumn{2}{c}{490} & \multicolumn{2}{c}{646} \\
\hline & a & b & a & b & a & b & a & b & a & b \\
$861^{\mathrm{c}}$ & 6.85 & 6.62 & 6.38 & 6.55 & 6.01 & 6.52 & 5.39 & 6.45 & 4.92 & 6.35 \\
$1231^{\mathrm{d}}$ & 6.73 & 6.28 & 6.66 & 6.32 & 6.54 & 6.34 & 6.03 & 6.27 & 5.85 & 6.24 \\
\hline \hline
\end{tabular}

${ }^{\mathrm{a}} K_{\Theta} \times 10^{3} / \mathrm{cm}^{2} \mathrm{~s}^{-1}$.

${ }^{\mathrm{b}} K_{\Phi} \times 10^{3} / \mathrm{cm}^{2} \mathrm{~s}^{-1}$.

${ }^{\mathrm{c}} K_{\text {CODATA }} \times 10^{3}=5.46 \mathrm{~cm}^{2} \mathrm{~s}^{-1}$.

${ }^{\mathrm{d}} K_{\text {CODATA }} \times 10^{3}=5.28 \mathrm{~cm}^{2} \mathrm{~s}^{-1}$.

$\left(r_{h}=1 \mathrm{~mm}\right)$, is nonnegligible with respect to the distance $d$ and thus $\epsilon$ may have a strong effect on the results. The resulting absolute error on $d$ is limited to the range -2 to +1 $\mathrm{mm}$ corresponding to a relative error on $K$ of $-13 \%$ to $+26 \%$ for $d=15 \mathrm{~mm}$.

Some new measurements were performed on the same Cecorite sample by decreasing the distance between the thermocouples to $d=9.3 \mathrm{~mm}$. Such a procedure allows us to check the coherence of the results in another way. These new measurements are presented in Table I together with the recommended values of the CODATA program ${ }^{2}$ at the corresponding temperatures. These new results lie outside the range of the main scattering of $\pm 10 \%$ around the fit. A new approach was intended to increase our understanding of these experimental results.

The $\Theta(u)$ and $\Phi(u)$ charts are convenient for the discussion as they allow in a single representation, a comparison between the $\Theta$ and $\Phi$ measurements obtained under various experimental conditions (different temperatures and

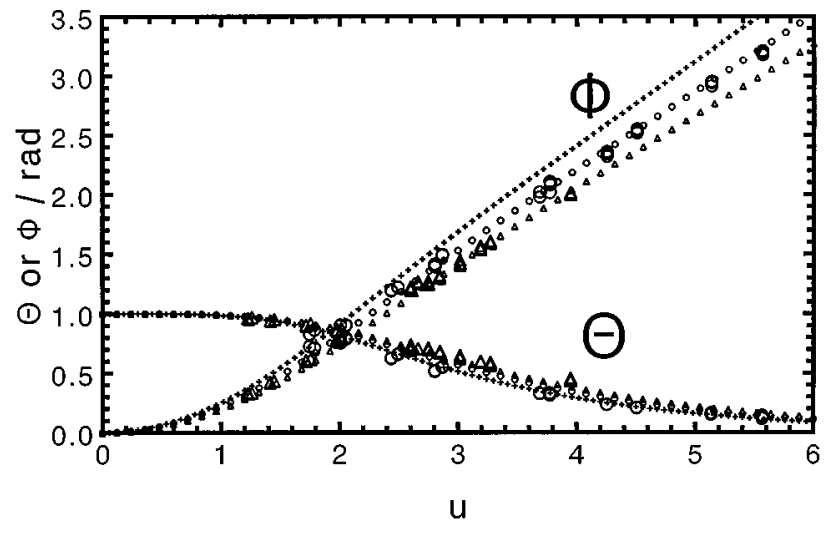

FIG. 1. Cecorite sample: +: ideal curves [Eqs. (1) and (2)], $\bigcirc: d$ $=13.2 \mathrm{~mm}$, large circles: experimental results, small circles: calculated values with Model I where $\epsilon_{1}=\epsilon_{2}=0.85 \mathrm{~mm}, \triangle: d=9.3 \mathrm{~mm}$, large triangles: experimental results, small triangles: calculated values with Model I where $\epsilon_{1}=\epsilon_{2}=1 \mathrm{~mm}$.

hence different diffusivity values, distances and frequencies).

Considering that the diffusivity value from the CODATA fit is the true value, each $\Theta$ and $\Phi$ measurement can be plotted versus its true $u$ quantity which is calculated from the diffusivity data issued from the CODATA fit at this temperature, and the $\omega$ and $d$ values. Such experimental plots are compared to the ideal ones [Eqs. (1) and (2)] in Fig. 1. A systematic shift between experimental and ideal curves, the magnitude of which depends on $d$, is observed, showing a systematic error.

In Fig. 1 are also plotted the results of the following model, which can simply account for this effect. This model gives the phase change and the amplitude ratio between the points $\left(r=\epsilon_{1}\right)$ and $\left(r=d-\epsilon_{2}\right)$ in the infinite cylinder. ${ }^{1}$

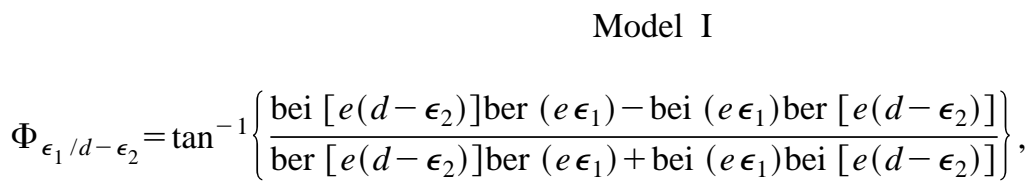

$$
\Theta_{\epsilon_{1} / d-\epsilon_{2}}=\frac{\sqrt{\operatorname{ber}^{2}\left(e \epsilon_{1}\right)+\operatorname{bei}^{2}\left(e \epsilon_{1}\right)}}{\sqrt{\operatorname{ber}^{2}\left[e\left(d-\epsilon_{2}\right)\right]+\operatorname{bei}^{2}\left[e\left(d-\epsilon_{2}\right)\right]}},
$$

where $e$ is the reciprocal thermal diffusion length ( $e$ $=\sqrt{\omega / K}$ ). Equations (3) and (4) reduce to Eqs. (1) and (2) as $\epsilon_{1}=\epsilon_{2}=0$.

Figure 1 shows that the experimental results on Cecorite $130 \mathrm{P}$ for two different values of $d$, at various frequencies and around two temperatures, are quite well fitted by the model. The $\Phi$ results are better fitted than $\Theta$ ones. It should be kept in mind that the model is very simple and that such an agreement significantly evidences the finite size effect.

Figure 2 shows the limiting curves which can be calculated by the former model, corresponding to the phase change and the amplitude ratio between the points $r=0$ and $r=d+r_{h}$ or $r=r_{h}$ and $r=d-r_{h}$ for each value of $d$. The comparison between Figs. 1 and 2, which are identically scaled, shows that all the experimental points remain in the range of the limiting curves.

\section{IMPERFECT THERMAL CONDUCTANCE BETWEEN THE SENSORS AND THE SAMPLE}

The finite thermal conductance at the interface between the sensors and the sample tends to decrease the amplitude ratio $\Theta$ and to increase the phase change $\Phi$ toward the values expected with a perfect contact. This effect has been experimentally tested, on a dense AL 23 polycrystalline alumina provided by the Degussa-France company. Alumina was chosen because it has been extensively studied, even if experimental data present a great deal of scatter. According to the manufacturer's data, the chemical analysis of our sample is $99.7 \mathrm{wt} \% \mathrm{Al}_{2} \mathrm{O}_{3}$ nominal and $99.5 \mathrm{wt} \% \mathrm{Al}_{2} \mathrm{O}_{3}$ minimal. 


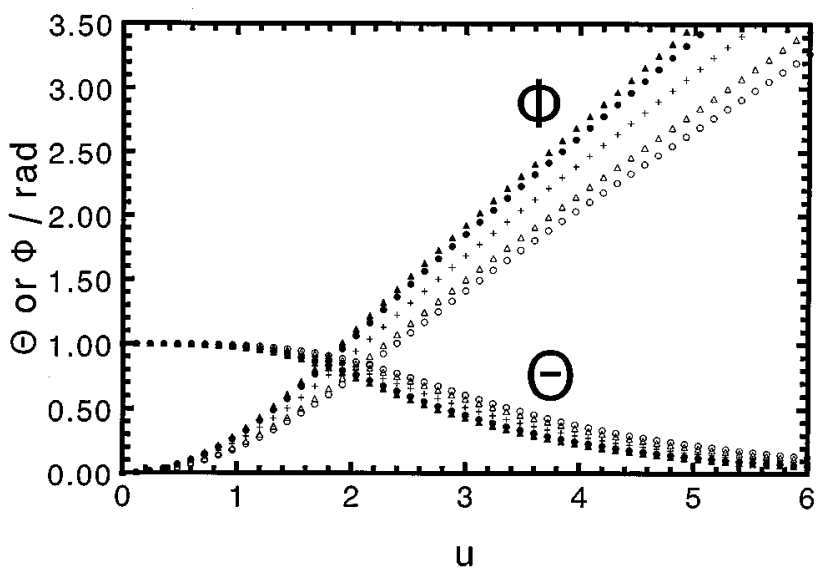

FIG. 2. Cecorite sample: + : ideal curves [Eqs. (1) and (2)], the other curves are calculated with Model I and $r_{h}=1 \mathrm{~mm}: d=13.2 \mathrm{~mm}: \bigcirc: \epsilon_{1}=\epsilon_{2}=r_{h}$, -: $\epsilon_{1}=0$ and $\epsilon_{2}=-r_{h}, d=9.3 \mathrm{~mm}: \triangle: \epsilon_{1}=\epsilon_{2}=r_{h}, \mathbf{\Delta}: \epsilon_{1}=0$ and $\epsilon_{2}=$ $-r_{h}$.

Its density lies between 3.7 and $3.95 \mathrm{~g} \mathrm{~cm}^{-3}$, with an average grain size of $20 \mu \mathrm{m}$. The sample is a cylinder of $35 \mathrm{~mm}$ diameter and $70 \mathrm{~mm}$ height, made up of a stack of disks of various thicknesses. This configuration minimizes the axial heat flow and allows easier drilling of the thermocouples' holes. The location of the outer thermocouple is $d$ $=14.5 \mathrm{~mm}$ from the center.

The diffusivity was measured at four temperatures (Table II) under argon and helium atmospheres. The pressure of the inert gas is about $300 \times 10^{2} \mathrm{~Pa}$ before heating. The approximate pressures at the measurement temperature are indicated in Table II.

Several diffusivity measurements reported in the literature for polycrystalline alumina, the density of which is close to that of our sample, were fitted versus temperature for comparison (Fig. 3). The details of the references are given in Table III. The density of the various samples lies in the range $3.7-4 \mathrm{~g} \mathrm{~cm}^{-3}$, except for Plummer ${ }^{6}\left(\rho=3.04 \mathrm{~g} \mathrm{~cm}^{-3}\right)$ and Paladino $^{7}\left(\rho=3.6 \mathrm{~g} \mathrm{~cm}^{-3}\right)$. Bonnerot ${ }^{8}$ and Fétiveau ${ }^{9}$ indicate for their samples, densities lower than $3.5 \mathrm{~g} \mathrm{~cm}^{-3}$. However, it is believed that the true densities of their samples are higher because they used the same dense AL 23 alumina as in the present study.

$$
\mathrm{K} / \mathrm{cm}^{2} \mathrm{~s}^{-1}=0.0103+0.189 \exp \left(-\frac{T / \mathrm{K}}{288}\right) \text {. }
$$
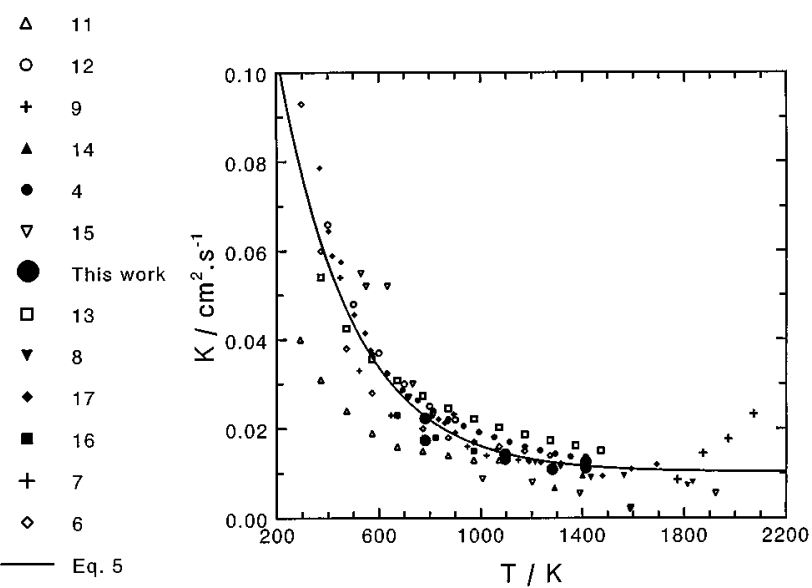

FIG. 3. The thermal diffusivity of dense polycrystalline alumina vs temperature. At each temperature, an average of the $K_{\Theta}$ and $K_{\Phi}$ values, over all the periods, is plotted.

Using the values calculated by Eq. (5) (Table II), and similarly as for the Cecorite results, experimental charts $\Theta(u)$ and $\Phi(u)$ are plotted in Fig. 4. The measurements performed under argon atmosphere can be fitted with a single curve independent of the temperature. The measurements carried out under helium atmosphere can be represented by two distinct curves depending on the temperature. This difference is mainly a temperature effect. Actually, the two measurements under helium are $631 \mathrm{~K}$ apart, resulting in very different heat transfer conditions (gas conductivity multiplied by 1.5 , radiation heat flux mulitiplied by 6 ) whereas the measurements under argon are only $186 \mathrm{~K}$ apart.

For all the temperatures, Fig. 4 shows that helium, the thermal conductivity of which is greater than that of argon (i.e., ten times at room temperature and atmospheric pressure $^{10}$ ), gives a lower $\Phi$ and higher $\Theta$. Moreover, helium at $1413 \mathrm{~K}$ gives a lower $\Phi$ and higher $\Theta$ than helium at 782 $\mathrm{K}$. All these observations are consistent with an improvement of the interfacial heat transfer when helium is used or when the temperature is raised. However, this simple reasoning does not take into account the fact that the contact conductance is the sum of three contributions acting in parallel, the magnitudes of which need to be estimated. Moreover, the conductivity of the sample plays a role in the contact phenomena. A quantitative analysis of the contact influence is presented in the following using a model which combines the

TABLE II. Diffusivity of AL 23 alumina obtained with $d=14.5 \mathrm{~mm}$. Each value is an average over at least three measurements.

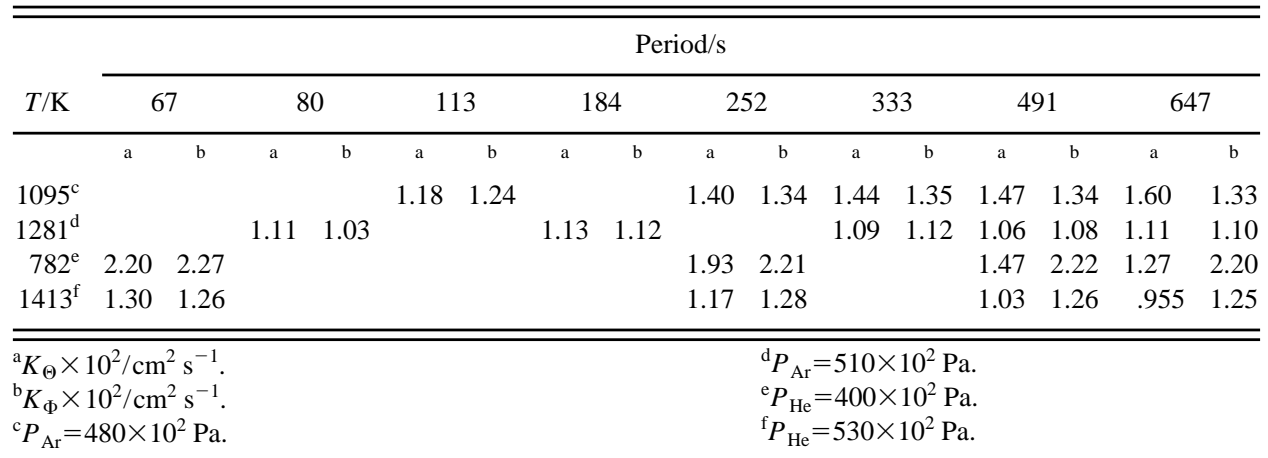


TABLE III. Thermal diffusivity measurements of dense polycrystalline alumina: overview of the samples, the methods, and the experimental conditions used by various authors. In some original papers, numerical values are not explicitly given hence they are deduced from the curves. List of the symbols used in the table; FF-front face, IR-infrared, $\mathrm{K}$-chromel-alumel thermocouple, $\mathrm{P}$-pressure, RF-rear face, S-Pt-Pt-Rh $10 \%$ thermocouple, and $\mathrm{t}-$ time.

\begin{tabular}{|c|c|c|c|c|}
\hline $\begin{array}{l}\text { Reference } \\
\text { and year }\end{array}$ & Sample & Method, procedure, and heater & $\mathrm{T}, \mathrm{P}$ & $\begin{array}{l}\text { Sensors and range } \\
\text { of error }\end{array}$ \\
\hline $11(1977)$ & $\begin{array}{l}\text { Sintered ALCOA A-16SG alumina, } \\
\rho_{\text {geom }}=3.93 \mathrm{~g} \mathrm{~cm}^{-3}, \mathrm{Al}_{2} \mathrm{O}_{3} 99.5 \%\end{array}$ & Flash, axial heat flow, laser & $298-1073 \mathrm{~K}$ & $\begin{array}{l}\mathrm{K} \text { thermocouple } \\
\text { attached to the RF } \\
\text { of the sample }\end{array}$ \\
\hline $8(1986)$ & $\begin{array}{l}\text { Degussit AL 23, } \rho_{\text {geom }}=3350 \mathrm{~kg} \mathrm{~m}^{-3} \text {, } \\
\text { disk: } \varnothing=10 \mathrm{~mm}, e=1.676 \mathrm{~mm}\end{array}$ & Flash, axial heat flow, Degiovanni method & $1183-1833 \mathrm{~K}$ & \\
\hline $13(1993)$ & $\begin{array}{l}\text { Sintered ALCOA A-16SG alumina }\left(T_{\text {sintering }}\right. \\
\quad=1873 \mathrm{~K})+ \text { graphite coating, } \\
\rho 1873=3.75 \mathrm{~g} \mathrm{~cm}^{-3}, \text { volumetric porosity } \\
\quad=0.058, \mathrm{Al}_{2} \mathrm{O}_{3} 99.79 \% \\
\text { disk: } \varnothing=12 \mathrm{~mm}-e=1.2 \mathrm{~mm}\end{array}$ & $\begin{array}{l}\text { Flash, axial heat flow, neodyme glass laser } \\
5-95 \mathrm{~J}, \lambda=1.067 \mu \mathrm{m}, \varnothing_{\text {pulse }}=16 \mathrm{~mm}\end{array}$ & $\begin{array}{l}373-1473 \mathrm{~K}, \\
\text { under } \\
\text { vacuum, Ar, } \\
\mathrm{N}_{2}, \mathrm{He}\end{array}$ & $\begin{array}{l}\text { IR In-Sb detector } \\
\mathrm{RF}, \lambda=5.5 \mu \mathrm{m}\end{array}$ \\
\hline $14(1963)$ & $\begin{array}{l}\text { Alumina }+ \text { carbone } \\
\text { coating on the FF, } \\
\rho=4 \mathrm{~g} \mathrm{~cm}^{-3}\end{array}$ & $\begin{array}{l}\text { Sine wave }(20-50 \mathrm{~s}) \text {, axial heat flow, phase } \\
\text { change measurement by photographing the face } \\
\text { of an oscilloscope, electron gun }\end{array}$ & $\begin{array}{l}1290-1400 \mathrm{~K} \text {, } \\
\text { under vacuum } \\
10^{-5} \mathrm{~mm} \mathrm{Hg}\end{array}$ & $\begin{array}{l}\text { FF and RF radiometers } \\
\text { calibrated against a blackbody, } \\
28 \%\end{array}$ \\
\hline $15(1972)$ & $\begin{array}{l}\text { Sintered alumina, } \\
\rho=3.95 \mathrm{~g} \mathrm{~cm}^{-3} \\
\varnothing_{\text {grains }}=20 \mu \mathrm{m} \\
\varnothing_{\text {pores }}=1 \mu \mathrm{m}\end{array}$ & $\begin{array}{l}\text { Square wave }(10-30 \mathrm{~s}) \text {, axial heat flow, phase } \\
\text { change measurement }+ \text { parameter identification } \\
\text { with confidence interval, } \mathrm{CO}_{2} \text { gas laser }\end{array}$ & $\begin{array}{l}530-1294 \mathrm{~K} \\
\mathrm{~N}_{2}+5 \% \mathrm{H}_{2} \\
\text { flow under } \\
1-5 \text { Torr }\end{array}$ & $\mathrm{PbS}$ IR detector \\
\hline
\end{tabular}

6 (1962) Alumina, Constant heat flux on a sample having initially a $\rho=3.04 \mathrm{~g} \mathrm{~cm}^{-3}$, slab section $=76 \times 127 \mathrm{~mm}^{2}$ uniform $T$, axial heat flow, recording of the $T$ on the FF and RF of the sample vs $t$, Joule effect in a chromel sheet $\left(5 \times 76 \times 180 \mathrm{~mm}^{3}\right)$

$298-1273 \mathrm{~K}$

$2 \mathrm{~K}$ thermocouples $(\varnothing=3.2$ $\mathrm{mm}$ ) spot welded to the 2 chromel sheet (heater and heat sink) which compose the sandwich assembly with the sample, precision $10 \%$, accuracy $15 \%$

17 (1967) Lucalox alumina, $\rho=3.89 \mathrm{~g} \mathrm{~cm}^{-3}$, $\mathrm{Al}_{2} \mathrm{O}_{3}>99.8 \%-\mathrm{SiO}_{2} 0.03 \%-$ $\mathrm{Fe}_{2} \mathrm{O}_{3} 0.01 \%-\mathrm{CaO} 0.01 \%$ $\mathrm{MgO} 0.1 \%$,

2 cylinders:

$\varnothing=25.4 \mathrm{~mm}-\mathrm{h}=152.4 \mathrm{~mm}$

$\varnothing=50.8 \mathrm{~mm}-\mathrm{h}=457.2 \mathrm{~mm}$

4 (1986) Mac Danel alumina, calculated $\rho=3.87 \mathrm{~g} \mathrm{~cm}^{-3}$, $\mathrm{Al}_{2} \mathrm{O}_{3}$ 99.8\%, cylinder: $\varnothing=54.1 \mathrm{~mm}-\mathrm{h}=139.7 \mathrm{~mm}$

16 (1950) Alumina, $\rho=3.8 \mathrm{~g} \mathrm{~cm}^{-3}$, porosity 0.05 , cylinder: $\varnothing=25.4 \mathrm{~mm}-\mathrm{h}=228.6 \mathrm{~mm}$

Scanning temperature with constant rate (1.5 $\mathrm{K} \mathrm{min}^{-1}$ ), radial heat flow, recording of the $T$ at 2 points of the sample vs $t, \mathrm{Pt}-\mathrm{Rh} 40 \%$ wire wound tubular furnace or $\mathrm{W}$ mesh heater

Scanning temperature with constant rate (1.5 $\mathrm{K} \mathrm{min}^{-1}$ ), radial heat flow, recording of the $T$ at 2 points of the sample vs $t$, horizontal resistance furnace

$-50 \mathrm{~K} T$ step on a sample having initially a uniform $T$, radial heat flow (infinite cylinder) recording of the $T$ change vs $t$, quenching from a Kanthal resistance furnace to a mixed liquid $\mathrm{Pb}$ bath

$250 \mathrm{~K} T$ step on a sample having initially a uniform $T$, axial and radial heat flow (finite cylinder), measurement of the slope of the curve $\ln (T)$ vs $t$ for 2 samples with different $\varnothing$, identification of the diffusivity and the Biot modulus, displacement of the sample from a Glo-bar element furnace $\left(T_{\min }\right)$, to a graphite resistance furnace $\left(T_{\max }\right)$
$808-1479$ or 368-1692 K under purified $\mathrm{He}$

$\mathrm{S}$ thermocouples inserted in 2 $(\varnothing=1.6 \mathrm{~mm})$ holes $11.4 \mathrm{~mm}$ distant, or, $4(\varnothing=2.3 \mathrm{~mm})$ holes, 7.1-14.3-23.5 mm distant, $10 \%$

573-1413 K, 2 sheathed $S$ thermocouples under $\quad(\varnothing=2.03 \mathrm{~mm})$ inserted in vacuum $10^{-2} \quad(\varnothing=2.39 \mathrm{~mm})$ holes 23.71 Torr $\quad \mathrm{mm}$ distant, $2.4 \%-5.4 \%$

673-973 K, S thermocouple in an axial air or liquid hole $(\varnothing=3 \mathrm{~mm}), 2.5 \%$

$\mathrm{Pb}$

1773-2073 K, W-Mo thermocouple in an constant axial hole $(\varnothing=3 \mathrm{~mm})$, He flow $6 \%$. 


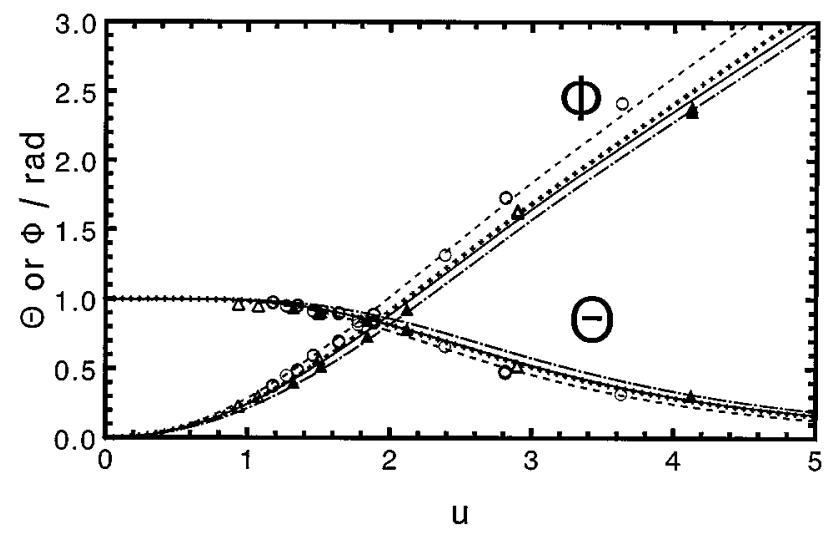

FIG. 4. Effect of the finite thermal conductance of the thermocouples/ sample contact under outer steady temperature. $H=0$ : perfect contact, $H$ $>0$ : imperfect contact.

effect of the sensors/sample conductance with the displacement effect.

Let the one-dimensional heat transfer equation in cylindrical coordinates, where $[T(r, t)]$ is the temperature at the radial position $r$ and the time $t$, be

$$
\frac{\partial^{2} T}{\partial r^{2}}+\frac{1}{r} \frac{\partial T}{\partial r}=\frac{1}{K} \frac{\partial T}{\partial t} .
$$

The heat transfer boundary conditions are described at the interfaces by the $H$ main coefficient (Fig. 5)

$$
\begin{aligned}
& r=\epsilon_{1}>0: \quad\left(\frac{\partial T}{\partial r}\right)_{\epsilon_{1}}=\frac{1}{H}\left[T\left(\epsilon_{1}, t\right)-T_{\mathrm{IT}}\right], \\
& r=d-\epsilon_{2} \quad\left(\frac{\partial T}{\partial r}\right)_{d-\epsilon_{2}}=\frac{1}{H}\left[T_{\mathrm{OT}}-T\left(d-\epsilon_{2}, t\right)\right] .
\end{aligned}
$$

$T_{\text {IT }}$ and $T_{\text {OT }}$ are the temperatures of the inner and outer thermocouples, respectively. The outer thermocouple is taken as the phase origin and unit amplitude yielding

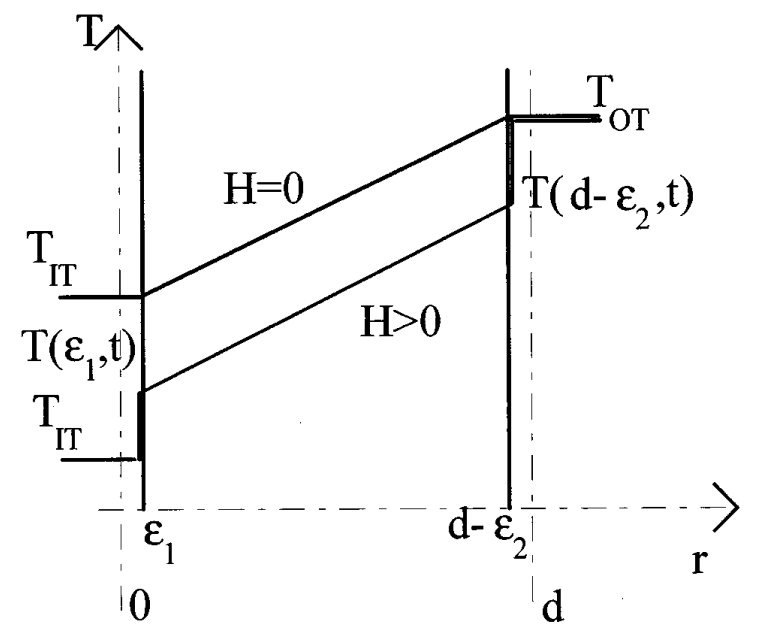

FIG. 5. Alumina sample: +: ideal curves [Eqs. (1) and (2)]. Experimental points: $\bigcirc$ : under argon $(1095$ and $1281 \mathrm{~K}), \triangle$ : under helium $(782 \mathrm{~K}), \mathbf{\Delta}$ : under helium $(1413 \mathrm{~K})$. ---: fit of the argon results. ——: Model II, $H$ $=1 \mathrm{~mm}, \epsilon_{1}=\epsilon_{2}=0.5 \mathrm{~mm}$. -----: Model II, $H=3 \mathrm{~mm}, \epsilon_{1}=\epsilon_{2}=0.5 \mathrm{~mm}$.

$$
\begin{aligned}
& T_{\mathrm{OT}}=\cos (\omega t), \\
& T_{\mathrm{IT}}=\Theta \cos (\omega t-\Phi) .
\end{aligned}
$$

Knowing the measured quantities, $\Phi$ and $\Theta$, the problem is to find the phase change $\Phi^{\prime}$ and the amplitude ratio $\Theta^{\prime}$ between the points $r=\epsilon_{1}$ and $r=d-\epsilon_{2}$. Using complex temperature $T^{*}$, the solution is quite straightforward and omitting the mathematical developments, the solution can be written as follows.

\section{Model II}

$$
\begin{aligned}
\Theta^{\prime} & =\frac{\left|T^{*}\left(\epsilon_{1}, t\right)\right|}{\left|T^{*}\left(d-\epsilon_{2}, t\right)\right|}=\frac{|\mathrm{NUM}|}{|\mathrm{DEN}|}, \\
\Phi^{\prime} & =\operatorname{Arg}\left[T^{*}\left(\epsilon_{1}, t\right)\right]-\operatorname{Arg}\left[T^{*}\left(d-\epsilon_{2}, t\right)\right] \\
& =\operatorname{Arg}(\mathrm{NUM})-\operatorname{Arg}(\mathrm{DEN}),
\end{aligned}
$$

where

$$
\begin{aligned}
& \mathrm{NUM}=\mathrm{A} I_{0}\left(e \epsilon_{1} \sqrt{i}\right)-\mathrm{B} K_{0}\left(e \epsilon_{1} \sqrt{i}\right), \\
& \mathrm{DEN}=\mathrm{A} I_{0}\left[e\left(d-\epsilon_{2}\right) \sqrt{i}\right]-\mathrm{B} K_{0}\left[e\left(d-\epsilon_{2}\right) \sqrt{i}\right], \\
& \mathrm{A}=\mathrm{C} \Theta \exp (-i \Phi)+\mathrm{D}, \\
& \mathrm{B}=\mathrm{E} \Theta \exp (-i \Phi)+\mathrm{F},
\end{aligned}
$$

and

$$
\begin{aligned}
& \mathrm{C}=e H \sqrt{i} K_{0}^{\prime}\left[e\left(d-\epsilon_{2}\right) \sqrt{i}\right]+K_{0}\left[e\left(d-\epsilon_{2}\right) \sqrt{i}\right], \\
& \mathrm{D}=e H \sqrt{i} K_{0}^{\prime}\left(e \epsilon_{1} \sqrt{i}\right)-K_{0}\left(e \epsilon_{1} \sqrt{i}\right), \\
& \mathrm{E}=e H \sqrt{i} I_{0}^{\prime}\left[e\left(d-\epsilon_{2}\right) \sqrt{i}\right]+I_{0}\left[e\left(d-\epsilon_{2}\right) \sqrt{i}\right], \\
& \mathrm{F}=e H \sqrt{i} I_{0}^{\prime}\left(e \epsilon_{1} \sqrt{i}\right)-I_{0}\left(e \epsilon_{1} \sqrt{i}\right) .
\end{aligned}
$$

In the above equations, $i$ is the complex number, $I_{0}$ and $K_{0}$ are the modified Bessel functions of zero order and $I_{0}^{\prime}$ and $K_{0}^{\prime}$ their first derivatives. $H$ is the ratio between the conductivity of the sample $\lambda$ and the conductance of the sensor/sample contacts $h$. It has the dimension of a length

$$
H=\frac{\lambda}{h} \text {. }
$$

$H$ always appears in the dimensionless form $e H$ [Eqs. (12) to (15)], which means that its effect in the calculation depends on the frequency of the thermal signal. Note $h$ is in fact a global heat transfer coefficient which takes into account conduction through the contact points or through the gaseous atmosphere and linearized radiating heat transfer. $H=0$ represents a perfect thermal contact; in this case the model yields obviously $\Theta=\Theta^{\prime}$ and $\Phi=\Phi^{\prime}$.

Assuming that the sensors/sample contact is nearly perfect under helium at $1413 \mathrm{~K}$, the experimental results obtained under these conditions are fitted using Model I [Eqs. (3) and (4)]. This procedure allows a rough estimation of the displacement parameters yielding $\epsilon_{1}=\epsilon_{2}=0.5 \mathrm{~mm}$. Then, the results of the measurements under argon atmosphere are fitted with Eqs. (3) and (4) and give a set of $(\Theta, \Phi)$ initial 
TABLE IV. Estimation of the $h$ parameter.

\begin{tabular}{|c|c|c|c|c|c|c|c|}
\hline & $H \approx$ & $\lambda \mathrm{Al}_{2} \mathrm{O}_{3}$ & $h \approx$ & $\lambda$ gas & $h_{\mathrm{gas}} \approx$ & $h_{\mathrm{rad}} \approx$ & $h_{\mathrm{sol}} \approx$ \\
\hline$T / \mathrm{K}$ & $\mathrm{cm}$ & $\mathrm{W} \mathrm{cm}{ }^{-1} \mathrm{~K}^{-1}$ & $\mathrm{~W} \mathrm{~cm}{ }^{-2} \mathrm{~K}^{-1}$ & $\mathrm{~W} \mathrm{~cm}{ }^{-1} \mathrm{~K}^{-1}$ & $\mathrm{~W} \mathrm{~cm}{ }^{-2} \mathrm{~K}^{-1}$ & $\mathrm{~W} \mathrm{~cm}{ }^{-2} \mathrm{~K}^{-1}$ & $\mathrm{~W} \mathrm{~cm}{ }^{-2} \mathrm{~K}^{-1}$ \\
\hline 782 & 0.1 & 0.11 & 1 & $0.0030^{\mathrm{a}}$ & $0.060^{\mathrm{a}}$ & 0.0055 & 0.9 \\
\hline 1095 & 0.3 & 0.072 & 0.2 & $0.00060^{\mathrm{b}}$ & $0.012^{\mathrm{b}}$ & 0.015 & 0.2 \\
\hline 1291 & 0.3 & 0.063 & 0.2 & $0.00067^{\mathrm{b}}$ & $0.013^{\mathrm{b}}$ & 0.024 & 0.2 \\
\hline 1413 & 0 & 0.060 & & $0.0047^{\mathrm{a}}$ & 0.094 & 0.032 & \\
\hline
\end{tabular}

data for the calculations by Model II [Eqs. (6)-(15)]. Finally, lists of $\left(\Theta^{\prime}, \Phi^{\prime}\right)$ values are calculated, using the estimated $\epsilon_{1}$ and $\epsilon_{2}$, for different $H$ values (Fig. 5).

It can be seen in Fig. 5 that the displacement effect, $\epsilon_{1}$ $=\epsilon_{2}=0.5 \mathrm{~mm}$, is approximately counterbalanced when $H$ $=1 \mathrm{~mm}$. To account for the shift between the results obtained under argon (1095 and $1281 \mathrm{~K})$ and helium atmosphere at $1413 \mathrm{~K}$, a value of $H=3 \mathrm{~mm}$ is necessary. This value cannot be considered as a measurement of $H$ at the sensor/thermocouple contact under argon around $1100 \mathrm{~K}$, only the order of magnitude is significant. For comparison, Paladino $^{7}$ (1957) reported $H$ values lying in the range 10-4 $\mathrm{mm}$ in the case of heat transfer through the surface of an alumina sample submitted to constant helium flow between 1773 and $2073 \mathrm{~K}$. This author also notices that this coefficient is "extremely sensitive to slight experimental variations" and that only a range of variation of $H$ can be reported.

In the above-mentioned case, the displacement of the thermocouples from their ideal position results in the decrease of the distance between them. The $H$ parameter may partially or even totally cancel this effect, depending on the relative values of $H, \epsilon_{1}$, and $\epsilon_{2}$. However, another case can be imagined, where the displacement increases the distance between the thermocouples; the two effects become now additive and an increase in $H$ will increase the measurement error.

It was mentioned before that the observed differences on the $(\Theta(u), \Phi(u))$ charts between the four temperatures were due to the changes in the contact conditions: nature of the gas and also increasing radiation heat transfer as the temperature raises. However, $(\Theta, \Phi)$ do not only depend on the contact conditions, i.e., on $h$, they also depend on the conductivity of the sample through the parameter $H$. This effect is non-negligible in the present case as the thermal conductivity of alumina is approximately divided by a factor of 2 between 800 and $1400 \mathrm{~K}$. The error on $(\Theta, \Phi)$ decreases as the sample conductivity decreases.

A priori estimation of the $h$ coefficient is difficult, this coefficient is the sum of three contributions; solid conduction through the contact points, gas conduction, and radiation

$$
h=h_{\text {sol }}+h_{\text {gas }}+h_{\text {rad }} .
$$

Among these three terms, $h_{\text {sol }}$ is the hardest to estimate. However, it is possible to try to use the $H$ values deduced from the experiments (Table IV) to check the order of magnitude of $h$.
From thermal capacity values ${ }^{18}$ and Eq. (5), with a theoretical density of $4 \mathrm{~g} \mathrm{~cm}^{-3}$, the conductivity is calculated as a function of temperature (Table IV). Dividing the $H$ experimental values by the $\lambda$ values, $h$ values are obtained (Table IV).

For the $h_{\text {gas }}$ term, relative information is given by the conductivities of the gas. The conductivities values reported in Table IV are extrapolated from the data of references ${ }^{19,20}$ at atmospheric pressure, to the temperatures of the measurements. This is an overestimation of the true values because the pressure in the present case lies in the range 400 $\times 10^{2}-530 \times 10^{2} \mathrm{~Pa}$. The gas conductance under argon is, at least, 5 times lower than that of helium. The temperature changes do not strongly modify conduction heat transfer by the gas compared to changing the nature of the gas. To know the magnitude of $h_{\text {gas }}$, it is necessary to know the average gap distance $g$ between the sample and the thermocouple bead. Knowing that the diameter of the bead is about $1 \mathrm{~mm}$ and the diameter of the hole is $2 \mathrm{~mm}$, this distance can be very roughly estimated as $g=0.5 \mathrm{~mm}$. Then, $h_{\mathrm{gas}}=\lambda / g$ is 20 times the conductivity value (Table IV).

On the hypothesis that the emissivity $E$ of the participating surfaces is close to $0.5,{ }^{21}$ the $h_{\text {rad }}$ term can be estimated by $h_{\mathrm{rad}}=4 E \sigma T^{3}$, where $\sigma$ is the Stefan-Boltzmann constant. Note $h_{\text {rad }}$ increases from 0.0055 to $0.032 \mathrm{~W} \mathrm{~cm}^{-2} \mathrm{~K}^{-1}$ between 782 and $1413 \mathrm{~K}$ (Table IV).

Finally, subtraction of the gas and radiation terms from the total conductance gives the solid conduction term $h_{\text {sol }}$ (Table IV). Note $h_{\text {sol }}$ is estimated in the range $0.2-0.9 \mathrm{~W} \mathrm{~cm}^{-2} \mathrm{~K}^{-1}$. The $h_{\text {sol }}$ values remain in the range $0.1-1 \mathrm{~W} \mathrm{~cm}^{-2} \mathrm{~K}^{-1}$, which is a classical order of magnitude for wavy metallic or nonmetallic surfaces in contact.

The models which have been developed show that the influence of displacement and conductance effects are indistinguishable, both contributing to the overall results. Obviously, the setup is improved as the diameter of the holes is decreased and the thermal conductance of the interface is increased. This is the main problem to be solved in order to increase the accuracy of the apparatus. At the present, the use of intrinsic split thermocouples directly welded on metallic samples, is under investigation. It is expected that this feature will greatly enhance the accuracy of our apparatus as it diminishes the influence of the contact conductance and divides the diameter of the thermocouples holes by two.

\footnotetext{
${ }^{1}$ J. Khedari, P. Benigni, J. Rogez, and J. C. Mathieu, Rev. Sci. Instrum. 66, 193 (1995).

${ }^{2}$ F. Cabannes and M. Minges, High Temp.-High Press. 21, 69 (1989).
} 
${ }^{3}$ W. Czarnetzki and W. Roetzel, Int. J. Thermophys. 16, 413 (1995).

${ }^{4}$ G. S. Sheffield and M. J. Vukovich, Jr., Ceram. Eng. Sci. Proc. 8, 1 (1987).

${ }^{5}$ W. Leidenfrost, Proceedings of the 8th Conference on Thermal Conditions, Purdue University, West Lafayette, Indiana, 7-10 October 1968 (Plenum, New York, 1969), pp. 213-227.

${ }^{6}$ W. A. Plummer, D. E. Campbell, and A. A. Comstock, J. Am. Chem. Soc. 45, 310 (1962).

${ }^{7}$ A. E. Paladino, E. L. Swarts, and W. B. Crandall, J. Am. Chem. Soc. 40, 340 (1957).

${ }^{8}$ J. M. Bonnerot (private communication).

${ }^{9}$ Y. Fétiveau, Thesis, Faculté des Sciences de l'Université de Lyon (France), 1961.

${ }^{10}$ D. R. Tree and W. Leidenfrost, Proceedings of the 8th Conference on Thermal Conditions, Purdue University, West Lafayette, Indiana, 7-10 October 1968 (Plenum, New York, 1969), pp. 101-124.

${ }^{11}$ D. Greve, N. E. Claussen, D. P. H. Hasselman, and G. E. Youngblood, Am. Ceram. Soc. Bull. 56, 514 (1977).
${ }^{12}$ B. Schulz, Kernforschungszentrum Karlsruhe, Primärbericht, 1-16 October 1987 (unpublished).

${ }^{13}$ W. Nunes Dos Santos and R. Taylor, High Temp.-High Press. 25, 89 (1993).

${ }^{14}$ J. M. Cerceo, ISA Trans. 2, 202 (1963).

${ }^{15}$ J. Schatz and G. Simmons, J. Appl. Phys. 43, 2586 (1972).

${ }^{16}$ E. S. Fitzsimmons, J. Am. Ceram. Soc. 33, 327 (1950).

${ }^{17}$ H. Chang, M. Altman, and R. Sharma, J. Eng. Power 7, 407 (1967).

${ }^{18}$ R. Castanet, High Temp.-High Press. 16, 449 (1984).

${ }^{19}$ B. Le Neindre, R. Tufeu, P. Bury, P. Johannin, and B. Vodar, Proceedings of the 8th Conference on Thermal Conditions, Purdue University, West Lafayette, Indiana, 7-10 October 1968 (Plenum, New York, 1969), pp. 75-100.

${ }^{20}$ R. W. Powell, C. Y. Ho, P. E. Liley, and R. C. Weast, Handbook of Chemistry and Physics, 54th ed. E2 (Chemical Rubber, Cleveland, 1974).

${ }^{21}$ A. Goldsmith, E. Waterman, and H. J. Hirschorn, Handbook of Thermophysical Properties of Solid Materials (Macmillan, New York, 1961), Vol. III. 